\title{
La aldea fantasma: \\ Problemas en el estudio del folklore y la cultura popular contemporáneos
}

\author{
LUIS DÍAZ G. VIANA \\ Departamento de Antropología. CSIC. Madrid
}

\section{RESUMEN}

El autor ofrece un análisis de la problemática relacionada con el estudio del folklore y la cultura popular en el mundo contemporáneo, transnacional e híbrido, aparentemente distinto de lo que se suponía que era el objeto/sujeto de estudio tradicional. Sin embargo, argumenta que el tipo de leyendas urbanas que podemos recopilar hoy a través de internet no es diferente de los materiales tradicionales, tales como leyendas, juegos o costumbres; ya que de lo que hablan éstos, al igual que aquéllos, es de las preocupaciones de las personas por dar sentido a un mundo siempre cambiante y siempre en contacto.

Palabras clave: Cultura popular, Leyendas urbanas, Netlore, Translocalización, Métodos antropológicos.

\section{SUMMARY}

The author analyzes the problems involved in the study of folklore and popular culture in a contemporary world, transnational and hybrid, aparently different from what the object/subject of study was supposed to be. Nevertheless he argues that the type of urban legends we can gather today through Internet does not differe from the traditional materials, such as leyends, games or mores, since they talk (as they used to) about people tryng to make sense out of an always changing and mixed world.

Key words: Popular culture, Urban legends, Netlore, Translocalization, Anthropological methods.

\section{ESTRATEGIAS PARA ENTRAR Y SALIR DE LO POPULAR}

Parafraseando a García Canclini, que subtituló su libro Culturas hibridas como Estrategias para entrar y salir de la modernidad (1989), podría decirse que las culturas en que actualmente vivimos también desarrollan

RDTP, LVIII, 1 (2003): 29-46 
- y no en menor medida - estrategias para entrar y salir de lo popular. Que esas culturas se caracterizan, en la práctica, tanto o más por lo segundo que por lo primero. Y que, en todo caso, tradición y modernidad no son aspectos tan reñidos como algunos creen.

Parece que lo culto y lo popular, lo rural y lo urbano ya no están donde estaban o ya no son como se nos había dicho que eran. Probablemente, las realidades que querían verse y estudiarse bajo tales denominaciones han cambiado casi tanto - a lo largo del último siglo- como los conceptos a través de los cuales pretendíamos comprenderlas. Se nos anima, para ver mejor, a utilizar todas juntas las clases de gafas (entiéndase métodos y técnicas) que nos han proporcionado las ciencias sociales o a quitárnoslas de golpe. Abandonemos, sí, las prenociones, los prejuicios. Pero la cultura - toda cultura - está hecha de ellos: es la gran estratagema de preconceptos que los seres humanos se transmiten. También los científicos, aunque sean "sociales" o — precisamente- por serlo.

Recuerda certeramente García Canclini, citando a Eliseo Verón, que "el discurso científico no está libre de los riesgos de la ideología, simplemente tiene instrumentos para cuestionar su modo de constituirse como objeto de estudio, las relaciones de lo textual y lo extratextual, o sea, el modo de construcción del discurso" (1989: 353).

Entremos a ver la casa de la cultura por una puerta u otra, por cada una de sus ventanas. Escalemos por la fachada si nos gusta el riesgo como invitaba a hacer García Canclini (1989: 358). No la reconoceremos. Quizá porque las culturas más que a casas se asemejan a cuerpos en movimiento, aunque - a menudo- se haya trabajado en nuestro campo sobre las fotografías estáticas que obteníamos de ellos, llegando a ignorar los cuerpos mismos.

En esta hora, en la situación actual, hay cosas que parecen verse mejor que antes y otras que se ven más confusas que nunca. Hablamos de culturas híbridas - como García Canclini- para referimos a la realidad cultural de nuestro mundo. Pero ¿cuándo la cultura no lo ha sido?, ¿cuándo no ha funcionado en la mezcla, en el intercambio, en la impureza, en la hibridez? La globalidad, la aplicación de innovaciones técnicas para informar o comunicarse tampoco es de ahora.

No podemos estar seguros $-\mathrm{y}$ ni siquiera vale la pena discutirlode que la generalización de los medios de comunicación y el uso de la informática, lo que se ha llamado "revolución massmediática" (Gubern 1987: 193), haya constituido una transformación mayor o menor respecto a lo que había antes de lo que pudieron serlo la invención de la escritura o de la imprenta. O cualquier otra innovación tecnológica de la humanidad. 
Estamos ahí. Tal es el paisaje. Y, sin embargo, en vez de intentar comprenderlo, hay quienes todavía nos advierten de que es preciso rescatar y preservar la cultura tradicional que estaría en trance de desaparecer ante la hipotética homogeneización impuesta por los medios de comunicación. Quienes nos presentan a esos medios y los nuevos vehículos de transmisión de la información como a los peores enemigos de una pretendida cultura tradicional y los principales causantes de su desaparición. Pero nos lo dicen, justamente, desde los mismos medios y desde sus propias páginas web con insistencia publicitaria y calculada periodicidad. Los ángeles custodios de la tradición, hoy, hacen su propio marketing y no descuidan una sistemática presencia en los periódicos, la televisión o la radio que garantice la captación de fondos públicos con rentabilidad política.

"El folklorismo - ha escrito Baussinger- parece preservar la cultura en su reivindicación de lo original y auténtico, rechazando la conexión entre cultura e industria que, en realidad, ha dado al folklorismo su peso" (Baussinger 1990: 105). Y, de hecho, el folklore-como concepto reinventado en el siglo XIX - no muere con la globalización ni con la industria global de la cultura, sino que se retroalimenta de las mismas y, quizá, nace en esa época de la confrontación con procesos que ya preludiaban, en cierto modo, estos fenómenos de globalización/diferenciación sobre los que ahora tratamos (Baussinger 1990: 151-160). La industria de la "autodiferenciación local", a la que se identifica con el patrimonio cultural y el desarrollo del turismo (pues, de hecho, son éstas cosas interconectadas), y a la que sirven, inventando y reconstruyendo exotismos, las asociaciones y centros dedicados a la recuperación de la cultura tradicional, se convierte -así- en "uno de los rasgos distintivos (globalmente determinados) de las postrimerías del siglo XX" (Beck 1998: 87).

Y no cabe duda de que, entre ese "acervo tradicional", del que algunos se han autoerigido en guardianes y valedores, hay cantidad de saberes y formas de expresión que merecen ser más conocidas e incorporadas a la realidad cultural del presente. La cuestión es si su labor -en la manera que la desempeñan y con el propósito que dicen llevarla a cabo- es necesaria para que de verdad tales manifestaciones pervivan (García Canclini 1989:195). Si muchas veces ese trabajo de "hombres de élite que, a través de la propaganda asidua se esfuerzan por despertar al pueblo e iluminarlo en su (santa) ignorancia" (García Canclini 1989: 196) no logra lo contrario de lo que se dice pretender: cambiar más rápidamente la vida de un supuesto pueblo tradicional, acelerar los procesos de transformación, alterar mediante la exotización intencionada de lo campesino aquello que entre sus habitantes era aún cotidiano y corriente. 
"A fin de cuentas — continúa diciendo García Canclini- los románticos se vuelven cómplices de los ilustrados. Al decidir que lo específico de la cultura popular reside en su fidelidad al pasado rural, se cierran a los cambios que la iban redefiniendo en las sociedades industriales y urbanas. Al asignarle una autonomía imaginada, suprimen la posibilidad de explicar lo popular por las interacciones que tiene con la nueva cultura hegemónica. El pueblo es rescatado pero no conocido" (García Canclini 1989: 196).

Pues por supuesto que la cultura popular puede aún servir para mucho. Sobre todo para pensar, para repensar cómo funciona en cada momento la cultura. No obstante, esa obstinación en que la pretendida cultura tradicional funciona aparte, en que sirve sólo como un museo virtual que debe descontextualizarse y clasificarse para volver a tener valor, empieza a resultar tan ridícula como perversa. Porque, además, tampoco podemos ignorar - salvo mediante una abstracción e idealización excesivas- que el habitante del medio rural que nos narra, hoy, historias de lobos es el mismo televidente que ha podido ver y oír relatos o películas sobre estos animales en el aparato que preside - como postmoderna imagen sagrada - su sala de estar. O el que, simplemente, ha leído en prensa alguna noticia sobre los ataques de estos animales no lejos de alguna "gran ciudad" como Madrid. Porque el regreso de los lobos no es - ya- una leyenda.

Y el que así lo quiera podrá seguir recogiendo relatos orales sobre ellos de labios de los viejos aldeanos, pero también los cuentan los más jóvenes y alguna leyenda he podido recopilar al respecto que me fue enviada, por una persona aún en la veintena, a través de un e-mail. Hablaba de un lobo que, en tierras de León, "hace de perro" hasta que, capitaneando una manada de congéneres, ataca a su propio amo, y aunque la narración tenía ciertas semejanzas en su moraleja última con el antiquísimo cuento de "El lobo malo" o "Lobo madrugador", recogido -entre otros- por Espinosa hijo (1987: 1, 65-66), también en un pueblo leonés, para la joven que lo envió estaba -evidentemente- de plena actualidad. $\mathrm{Y}$ es, en su mayor parte, una leyenda nueva que trata, desde un viejo asunto, nuevos problemas.

\section{RESPUESTAS EN CLAVE "FOLK" A LA GLOBALIZACIÓN}

Más allá de lo que se nos vende como tradicional desde la industria de las diferenciaciones, hoy podemos considerar como folklore aquellas expresiones contemporáneas de la cultura que servirán para comprender 
lo que en una sociedad pasa, no sólo cuáles son sus tensiones, sino -incluso- hasta dónde llega el delirio producido por las dolencias que padecemos.

Pues, como - acertadamente- ha señalado Martha Blache, "a partir de las nuevas orientaciones, los folkloristas han recuperado los objetivos disciplinarios originales" (Blanche 1999: 11) de los que el folklorismo se habría alejado perversamente en su tendencia a la autocomplacencia y al utilitarismo más ramplón. "Lo han logrado — prosigue la misma autoraatendiendo a la relación entre folklore y sociedad, a sus respectivas transformaciones e interdependencias, a las diferentes esferas de la comunicación - cara a cara, pública y mediatizada - y a los modos en que los saberes tradicionales tienen de codificar y poner simbólicamente en funcionamiento elementos de la modernidad. Todo esto ayuda a comprender la vida social en el mundo moderno" (Blache 1999: 11).

Folklore, desde esa perspectiva, serían también - y como luego veremos- los últimos chistes o las nuevas danzas callejeras, pero también las "pintadas" y los bulos que circulan en cualquier medio. Un folklore síntoma de todas las crisis, entre la cultura de masas y las performances generadas por "pequeños grupos" (Ben-Amos 1971). Un folklore de -y sobre- la globalización.

Frente a la desarticulación aparente de lo pequeño reaparecería el folklore -no únicamente su simulacro o apariencia, su pastiche con pretensiones de autenticidad y un precio en el mercado-. Un folklore que - en unas ocasiones- puede parecer reaccionario, pero - en otras- contestatario y subversivo, que contamina el corazón de lo global y utiliza sus mismas armas: los nuevos espacios informáticos.

Al mismo tiempo que se revaloriza lo "artesanal" y "lo tradicional" por los mismos medios de comunicación que (según algunos folkloristas) habrían de terminar con todo el folklore hasta ahora existente, nace o resucita cotidianamente un folklore nuevo, se viven y se intentan articular respuestas desde el folk, desde el grupo que comparte algo en común. Y ese es el verdadero desafío: no tanto coleccionar y clasificar las antiguallas en desuso, sino explicar un fenómeno que no cede sino que se multiplica, que se transmite ahora por los más modernos vehículos de comunicación.

La gente sigue inventando: rumores, bulos, leyendas... Hay una capacidad infinita de contestación en los folks, en esos nuevos folks que se crean y buscan identificarse en el laberinto del ciberespacio; en esas culturas glocales que —que según apuntaran ya Appadurai (1996) y Beck (1998) - se están abriendo paso y no están vinculadas muchas veces a ningún lugar ni tiempo, que carecen de un contexto convencional porque se agrupan e identifican en torno a nuevas diferencias. 
Una capacidad para responder a los problemas de cada época, para idear bombas imaginativas que atenten contra la aparente consistencia de las tendencias que se presentan como dominantes, para tejer sutiles sabotajes contra los sistemas que intentan convertirse en totalitarios, ya sea en el campo de la economía, de la cultura o del pensamiento.

Hay una inventiva prodigiosa en ese folk que podemos ser todos (Dundes 1977) para poner piedras en los grandes engranajes, para hallar respiro entre los resquicios de las máquinas de dominio, para seguir haciendo lo que queremos aunque no sea políticamente correcto. Eso es cultura popular y folklore también. Es, quizá, el motor mismo, el hálito último de lo que se considera popular. Aunque lo que se venda sean los productos tenidos como tradicionales y - como mucho- la memoria congelada en video de los viejos oficios.

Como escribió lúcidamente a este respecto Antonio Gramsci en sus observaciones sobre el folklore, en lo que éste tiene de "concepción del mundo y de la vida" y no sólo de "elemento pintoresco", cabe distinguir varios estratos: "los fosilizados, que reflejan condiciones de vida pasada y, por tanto, son - a menudo- conservadores y reaccionarios, y otros que son una serie de innovaciones, creadoras y progresivas, determinadas espontáneamente por formas y condiciones de vida en proceso de desarrollo, y que se encuentran en contradicción o meramente en discrepancia con la moral de los estratos dirigentes" (1988: 489).

De esto se trata. De cómo el folklore no sólo se perpetúa, sino también de cómo se reinventa. De su capacidad no para sobrevivir desde el pasado, sino para adaptarse al presente y preludiar el futuro. De la habilidad de los folks para conservar viejas identidades y crear otras nuevas, para encontrar rasgos en común que los cohesionen, de la imaginación colectiva que busca una salida entre las rendijas de los mastodónticos edificios que amenazan ruina. Del sentido común para encontrar un sentido particular a lo propio. De la capacidad humana para crear lo no convencional, para inventar lo inesperado. Para formular la disidencia que, por pasar casi desapercibida, puede ser la más resistente.

De todo esto también tenemos que ocuparnos, del folklore del futuro recompuesto con los más viejos pero útiles retazos de la discrepancia y la subversión. El rumor popular que causa pérdidas a las multinacionales, los mensajes que nos advierten de la invasión de todos los virus, la fiesta popular inventada en una playa para celebrar el vetusto San Juan al margen de las normas y los "evacuatorios festivos" dispuestos por las autoridades...

Se trata de ese otro folklore que tiene que ver con la capacidad de crear. De la cultura popular como estrategia — también — para escapar de 
las imposiciones, para seguir haciendo "lo que nos da la gana", para engañar las normas de lo establecido. Se trata de ese vaga pero cierta posibilidad que tenemos todos de resistir e inventar. De un folklore al que no se puede apresar en vitrinas porque nunca se rinde ni pierde su utilidad. El folklore que jamás muere.

\section{LA DECONSTRUCCIÓN DE UNA VIEJA DICOTOMÍA: FOLKLORISMO CASTICISTA VERSUS MODERNIDAD}

Sin duda, quienes esperen encontrar en la presente exposición recopilaciones o estudios sobre lo que - todavía- muchos en nuestro país entienden como el único folklore posible (viejas canciones, antiguas leyendas, atávicas danzas, arcaizantes tradiciones, supersticiones ancestrales) se sorprenderán ante la mayoría de los temas aquí abordados y el enfoque de los trabajos a los que voy a referirme. Y experimentarán cierta sorpresa no únicamente por las líneas de investigación que aquí se apuntan - así, los trabajos realizados en USA sobre las leyendas acerca de la comida rápida que hoy circulan en tantas grandes ciudades-, sino también por los ensayos de redefinición de la disciplina que varios de los autores a los que voy a referirme se atreven a proponer.

Porque, en efecto, hay algunos de ellos que - como Ben-Amos (1971) o Dundes (Dundes y Pagter 1978) _ "osan" poner en tela de juicio la especificidad que para la caracterización del folklore puedan tener conceptos como el de la "tradición" o la "oralidad". De otra parte, la cultura popular —en cuanto a cultura de masas - y el folklore —en cuanto a saber transmitido dentro de "pequeños grupos" - tampoco aparecerán aquí como realidades necesariamente contrapuestas o irreconciliables. Y es que cada vez se hace más difícil sostener esa creencia de los folkloristas decimonónicos en algo así como la "cultura tradicional", en cuanto a objeto específico e independiente de estudio científico, salvo que hablemos del pastiche remendado y "puesto en escena" que los profesionales del folklorismo ofertan al mercado. Más que una "cultura tradicional" hay "tradiciones dentro de una cultura", lo que no es exactamente lo mismo.

Además, otros aspectos sacralizados por el folklorismo como la "ruralidad", la "antigüedad" y la "pureza" (de las tradiciones) pierden -asimismo- el valor definitorio y excluyente que se les ha querido dar en muchas regiones y países de Europa cuando, según ocurre en muchos de los trabajos realizados sobre cultura popular en los últimos tiempos y que nos servirán de textos de referencia, se habla ya sin ambages de un "folklore urbano" que se estaría creando ahora mismo, nada rural, 
nada antiguo y nada puro, ya que en él se cruzan y entremezclan muy distintas vertientes de transmisión de la cultura. Un folklore inventado entre nosotros -o por nosotros mismos- en los umbrales propios de la postmodernidad.

Igualmente pueden sorprenderse ante estos tratamientos renovadores de la cultura popular quienes, con una mirada formada en el recelo cosmopolita, se han acostumbrado a identificar el folklore -en parte por todo lo que muchos adalides del folklorismo dicen que es- con una defensa de los valores más rancios, de los rituales más bárbaros y de los cantos u objetos en franco desuso. Así, para gran parte de los que pretenden situarse en el progresismo y la vanguardia, un folklore como el que en España generalmente parece reivindicarse por los "adoradores de la tradición", no podría sonar sino a arcaísmo y atraso: la apología de la matanza del cerdo o del "tradicional" maltrato de gallos y toros, la cultura de la morcilla, la filosofía del botijo, la estética del refajo o la musicalidad de los cencerros y de los tintineos de la botella de anís. Daría la impresión de que los "salvamentistas" del folklore, que ponen el grito en el cielo ante la que ellos mismos consideran inminente desaparición de costumbres tenidas por autóctonas, estarían concentrando sus esfuerzos en un objeto de estudio destinado a desaparecer, con lo que no puede pensarse que su disciplina o profesión tenga mucho futuro si se limita a eso. Salvo que el recuperador de tradiciones lleve su función a las últimas consecuencias, no sólo guardando, también inventando la tradición que - de hecho- es lo que suele ocurrir.

En todo caso, estos meros aplicadores de una receta de recopilación mediante la que se pretende preservar lo "rural", lo "oral", lo "antiguo" y lo "propio" no podrían ser vistos como partidarios de la modernidad, sino más bien como sus enemigos. Sin embargo, folklore, para folkloristas como los que más han influido en USA durante las últimas décadas, serán también las formas de expresividad que los grupos de niños o jóvenes de los barrios multiétnicos de las ciudades más "modernas" y populosas resultan capaces de crear día a día. Las danzas callejeras e, incluso, los chistes y leyendas que corren por las redes de Internet.

Pero también en España circulan, desde hace tiempo, las mismas o parecidas "leyendas urbanas" que en USA sobre la "dudosa carne" que aparecería en los restaurantes chinos o en las hamburgueserías y, posiblemente, por iguales o muy parecidas causas: la verosimilitud que encuentran las invenciones sobre un tipo de comida y otros muchos aspectos de nuestro mundo respecto a los que la gente corriente se siente suspicaz porque ha perdido el control de lo que se cocina y se come, que es lo mismo que decir sobre cómo se trabaja y se vive (Ortí y Sampere 2000: 175-280). 
Escribe Gary Alan Fine en su ejemplar trabajo sobre el "Kentucky Fried Rat" a propósito de las ratas supuestamente servidas como pollos en los restaurantes de la famosa cadena:

Esta leyenda refleja un cambio en el sistema de valores. Las cadenas de comida rápida no han proliferado sin la aceptación del público. El creciente énfasis de la vida norteamericana en el ocio y el cambio en el papel de las mujeres hace que los restaurantes de comida rápida sean posibles y probablemente necesarios. Sin embargo, estos cambios en la orientación de los valores tuvieron efectos psicológicos, ya que las personas en periodos de transición no se han reconciliado completamente con los cambios estructurales que estos nuevos valores implican. Los nuevos valores coexisten, y en algunos casos se contradicen con los valores tradicionales (Fine 1992: 120-137).

Sin hablar, ya, del batallón de "autoestopistas fantasmas" que paran a los automovilistas en nuestras carreteras (Ortí y Sampere 2000: 295-304) o del "perro del Ganges" —en realidad una rata gigantesca- que turistas inadvertidos traen desde la India como animal doméstico a sus pisos "de diseño" de Madrid y Barcelona y que el animalito se dedica a destrozar. Curiosamente, esta leyenda acerca del también denominado "Perro extranjero" me fue contada por dos antropólogos, en diferentes lugares, como "historia totalmente cierta" (Díaz G. Viana 1997: 153). Con posterioridad a la publicación de estas versiones, Ortí y Sampere recogerían otros ejemplos sobre el mismo tema: en el primero de ellos el extraño animal -una rata gigante o mutante tomada por un perro- procede de Alemania, y en el segundo de "un país tropical" (Ortí y Sampere 2000: 285-291).

Incluso, han surgido relatos inverosímiles - difundidos a través de Internet- sobre lo que habría ocurrido en un programa de TV que se dedicaba a "sorprender" a las personas y lo más interesante es que la descabellada historia fue creída por tanta gente que quienes hacían el programa tuvieron que desmentirlo públicamente. En este relato -genial en lo que tiene de parodia y sarcasmo sobre los actuales programas de TV_, el perrito tampoco era tan "inofensivo" como parecía, y terminaba chupando con deleite las partes genitales de una adolescente untada para la ocasión con mermelada o foiegras (según las versiones):

Los padres de una niña querían dar una sorpresa a su hija que era fan de Ricky Martin. Para tal fin se pusieron en contacto con el programa de Antena 3 Sorpresa, ¡sorpresa! que ocultó varias cámaras en el domicilio y escondió a Ricky Martin en un armario. Los padres se personaron en el plató para ver la reacción de su hija en directo, pero pronto se quedaron mudos al comprobar cómo ésta salía de la ducha, se encaminaba a la nevera, sacaba un bote de mermelada de fresa y llamaba a su perro para que empezara a lamerla (Ortí y Sampere 2000: 167). 
La lluvia de supuestos "aerolitos" que cayó sobre España en los primeros meses del año 2000 adoptó pronto los ropajes y diversidad de la leyenda urbana, de manera que —al final- ya había testimonios de personas que decían verlos hasta en forma de botella de Coca-cola. Nadie reconoció, sin embargo, en el fenómeno los mecanismos de la creación folklórica ni consideró conveniente estudiar el fenómeno desde ese punto de vista.

¿ESCRIBIENDO DE TODO DESDE NINGUNA PARTE?: LA CULTURA POPULAR DE LOS "NO-LUGARES"

Todo ello nos debería hacer pensar que los resortes que hacen posible el folklore siguen funcionando plenamente en nuestro mundo. Que el folklore puede estar de actualidad. Y que sigue sirviendo socialmente tanto de expresión de tensiones profundas como de válvula de escape que ayude a liberarnos de ellas. Las leyendas sobre -y en contra dela comida rápida han ocasionado pérdidas "reales" a las grandes compañías y las invenciones escabrosas acerca de determinados programas televisivos han contribuido -quizá- a la retirada de los mismos o, al menos, han generado en torno a ellos una polémica negativa (Ortí y Sampere 2000: 168-172). Parodiando una canción "pop" muy conocida, podría decirse que el folklore también "mata a las estrellas de la televisión".

Pero que ni unos ni otros - los que, para simplificar, podríamos llamar "cosmopolitas" y "defensores del terruño", "vanguardistas" y "tradicionalistas a ultranza" - se llamen a engaño. No se trata de presentar en este trabajo, una vez más, recetas y soluciones que sólo por venir -aparentemente- de fuera se supone habrán de ser más innovadoras y mejores.

Es verdad que el estudio del folklore ha propiciado en USA un desarrollo y discusiones que apenas se conocen en España, pero también aquí -aunque casi siempre con escaso eco y en poco número- ha habido autores que, desde hace tiempo, han propuesto líneas de investigación parecidas a las de estos autores norteamericanos, e incluso con anterioridad.

La aproximación de Julio Caro Baroja a los pliegos españoles de cordel, entre otros temas de la cultura popular a los que dedicó su atención (como el folklore de las ciudades), nos depararía - por ejemplo- un conjunto de interesantes consideraciones sobre las conexión entre la cultura de masas y el folklore, así como un modelo pionero para hacer lo que otros, por la misma época o un poco después, llamarían sociología y antropología de la literatura (Caro Baroja 1988). 
Los desencuentros a que se refieren algunos folkloristas norteamericanos entre antropólogos, folkloristas académicos y quienes se dedican a lo que en USA se identifica como "folklore público", también se han producido aquí. Mi opinión particular es que el diálogo entre "los profesionales del estudio de la cultura" y los profesionales de la cultura - en este caso de una cultura recreada artificialmente como es el folklore que el folklorismo nos "vende" - resulta poco menos que imposible. A los segundos, en nuestro contexto, la discusión teórica sobre la naturaleza de su trabajo no sólo no les atrae, sino que - probablemente- les estorba, empeñados como siguen en el rescate de artefactos, la invención de señas de identidad o en proporcionar reclamos de interés turístico.

Sin embargo, hay que reconocer que las estrategias de implantación y desarrollo de la antropología en España han podido estar bastante equivocadas - o no ser demasiado hábiles- en este terreno, pues —al autoexcluirnos de demasiados foros e insistir tanto en lo que no éramos- los antropólogos hemos cedido un enorme espacio a la práctica indiscriminada del folklorismo. Lo que resulta especialmente grave, además, si tenemos en cuenta que una antropología "española" - y no de procedencia exclusivamente foránea, tendente a un "antropologismo" que maquinalmente reproduce modelos y jergas de otros- no debería sino engarzarse y reconocerse en la tradición etnográfica anterior —en gran parte dirigida a los estudios de folklore- y que ya contaba con suficientes trabajos de valor e investigadores serios. Sobre todo, cuando el trabajo para el que siguen siendo requeridos los antropólogos aquí —y el ámbito casi exclusivamente autonómico o nacional en que, por varias razones, la mayoría tienen que realizar su trabajo- continúa abocándoles a temas, intereses y demandas muy relacionados con el estudio del folklore y la cultura popular.

Pues ¿desde dónde se escribe antropología, hoy? ¿Desde qué —o sobre cuál- lugar, se sitúan los antropólogos para hablar de otras culturas o de la suya propia? Si es que acaso no están hablando siempre en referencia a su cultura. Sabemos de qué hablan: casi de cualquier cosa que tenga que ver con la sociedad y la cultura y no sólo con aquellos pueblos supuestamente "primitivos" de los que se ocupaban mayoritariamente antaño. Conocemos también cómo escriben sus textos: en forma de monografías o de ensayos, abstrayendo, teorizando, ya, más que comparando, sobre trabajos de campo propios o de otros.

Pero, ¿desde qué territorio escriben y construyen sus discursos acerca de pueblos que son o fueron, acerca de lo general y particular en las culturas o de las leyes universales -nunca encontradas- por las que se regirían la historia y las invenciones de la humanidad? Se les ha repro- 
chado en alguna ocasión - a Geertz y a otras cabezas visibles de la antropología actual- que no se sabe desde dónde y, a veces, ni siquiera para quiénes escriben. Se les ha acusado - también- de escribir desde ninguna parte y para ninguna parte, de resultar crípticos y poco útiles, de no proporcionar - ni ser capaces de comunicar- "recetas" mostrencas con que arreglar el mundo.

Parece que la antropología se escribe desde fuera y desde dentro, entre lugares y entre culturas o entre tradiciones, sobre y desde intersecciones culturales. Que las más de las veces incomoda porque hace pensar sobre las sinrazones de la propia cultura, que critica más que soluciona, que sugiere preguntas más que proporciona respuestas. Parece que la antropología es escrita, en gran medida, "desde el exilio" (García Canclini 1997: 3-22).

Los mismos antropólogos han ironizado a menudo sobre esa condición, que se supone consustancial a la identidad de su oficio, de "sentirse extraños" hasta entre los suyos, de ser una especie de "extraños profesionales" (Agar 1980) o profesionales de la extrañeza. Y es de temer que la antropología sólo pueda escribirse, en efecto, sabiéndose casi igual de extraño en todas partes, desde un "no-lugar" distinto a ese "no-lugar" que -al tiempo- es todos los lugares (o como todos los lugares) del que hablan quienes se refieren a la "sobremodernidad" del mundo actual. El "no-lugar", tan frecuente en nuestra época, de los aeropuertos y los supermercados.

El antropólogo escribe desde un "no-lugar" y un "no-tiempo" bien diferentes a los de esa "sobremodernidad": desde un lugar que no existe en el presente, que pertenece al pasado y al futuro, que los relaciona para siempre. La antropología no puede escribirse para complacer a nadie, para fabricar identidades o para reinventarlas (aunque también trate en ocasiones, críticamente, de ello). Si lo hace, por muy minuciosa que sea y bien construida que esté, me temo que caerá fácilmente en los terrenos de la fontanería social, de un antropologismo henchido de jerga tecnicista, o del autocomplaciente folklorismo. Si se escribe pensando en tranquilizar a aquellos sobre los que se habla y a los que se pretende estudiar, se traicionará -inevitablemente- a sí misma.

Escribir "en antropología" es hablar con libertad -y, con frecuencia, críticamente- de cómo funciona una cultura. Y hablar de esto es hablar de las relaciones de poder. Algo que quizá sólo puede hacerse desde fuera, desde un "no-lugar" exclusivo para testigos lenguaraces. Justamente, desde un territorio no lejano al que frecuentan los creadores de "bulos" intencionados, los hacedores de leyendas contemporáneas, el reino de la lucidez disidente, el purgatorio de los observadores insobornables. 
Cuando Gary Alan Fine propone en el trabajo ya citado (Fine 1992) "que se debería prestar más atención a las características performativas y contextuales del folklore urbano", peca - a mi juicio- de ingenuidad al añadir que "por ejemplo, se podría realizar un estudio etnográfico de las cadenas de comida rápida, grabando las conversaciones entre clientes y entre empleados" (Fine 1992: 137). No alcanzamos a imaginar qué pinta un etnógrafo con grabadora en una hamburguesería donde, además de lo difícil que sería recoger ninguna conversación inteligible, apenas se habla. Y menos - si se hace- del contenido que puede haber en las hamburguesas.

Las leyendas sobre ese $\mathrm{u}$ otros temas no se crean ni se transmiten - generalmente- allí. Convencionalmente, pensamos que pueden ser los consumidores de hamburguesas quienes nos hablarán sobre esos asuntos y cándidamente nos dirigiríamos grabadora en ristre hacia ellos. Sin embargo, habría que tener en cuenta que todos consumimos hamburguesas alguna vez, pero nadie está consumiendo siempre hamburguesas. La cultura popular, de otro lado, se transmite tanto o más, hoy en día, por vías informáticas — de fax o de fotocopia (y todo junto) - que oralmente. Intentar recopilarla como si sólo se siguiera transmitiendo por tradición oral probablemente sea un método equivocado en el que quienes pretenden hacer antropología sobre las leyendas urbanas fácilmente pueden incurrir. La idea de que el trabajo de campo consiste sólo en ir con una grabadora en la mano registrando historias de vida, relatos o versiones orales de algún tema folklórico tiene que ser profundamente revisada.

El folklore actual parece estar en todas y ninguna parte. Es relato oral, $e$ mail y noticia que sale en los periódicos. Para descubrirlo - e incluso verlo- hay que recurrir a una pluralidad de fuentes y combinar muy distintas clases de información: de lo informático a lo oral y de la televisión a la calle.

\section{EL ESTUDIO DE COMUNIDADES Y EL SABER "DESLOCALIZADO": ¿ANTROPOLOGÍA DE LA "ALDEA GLOBAL" O DE LA "ALDEA FANTASMA"?}

¿Cómo estudiar comunidades, hoy, desde las perspectivas que anteriormente se han expuesto? Ello exigirá poner a prueba tanto los planteamientos teóricos y metodológicos propios de lo que se ha denominado "estudio de comunidad" y que se ha aplicado principalmente sobre comunidades rurales como los presupuestos y metodologías que se han empleado en la llamada "antropología urbana", pues de las dos convenciones de "rural" y "urbano" participan, en la actualidad, una gran parte de pueblos. Sin olvidar tampoco las recientes aproximaciones al estudio 
de la cultura popular y "conocimiento local" en contacto con la globalización. Es decir, la relación y dependencia entre los niveles local y global, así como el fenómeno conocido como "glocalización". Hoy, quizá más que nunca, puede decirse que "las culturas no son muros y se caen teóricamente las fronteras" (García 2001). Las líneas que diferencian el "lugar etnográfico" y el "no lugar" (Augé 1995) no resultan en muchos casos tan nítidas como, sobre el papel, pudiera parecer. Y menos aún en las comunidades "deslocalizadas" donde los paradigmas de ciudad/campo, urbano/rural, local/global aparecen envueltos en un complejo proceso de transformación que tiende, irremisiblemente, a desdibujar sus aparentes características. En paralelo, puede apreciarse que la propia antropología, en cuanto a disciplina que pretende estudiar esos procesos, da - a veces- la impresión de cuestionar y reificar sus contornos en la medida que el objeto de estudio se complica y amplía: "Como si determinados rasgos de su identidad, lejos de adquirir una cada vez mayor definición, con el tiempo hubieran ido perdiendo nitidez" (Sánchez Pérez 2001). La solución probablemente no esté en rechazar como objeto los procesos y comunidades que ofrecen más dificultades sino, por el contrario, en encararlas, desde la realidad de un pueblo o comunidad concretos que pongan - en sí- en tela de juicio los viejos paradigmas, averiguando mediante su estudio hasta dónde puede llegar la antropología con sus métodos en el análisis de un caso problemático. Aceptando, en suma, el desafío de comprobar qué es lo que puede aportar esta disciplina científica respecto a (o en colaboración con) otras, desde ese enfoque holístico que - en sus planteamientos, al menos- siempre la ha caracterizado.

Se ha empezado a reflexionar recientemente sobre el hecho de que en la elección del objeto de estudio y -más en concreto- del lugar, comunidad o pueblo que el antropólogo optá por estudiar juegan muchos más aspectos y más importantes de los que reconocemos o de los que somos conscientes al comenzar nuestro trabajo de campo. Lo importante, también se ha pensado, es el método y no el objeto, pero en la selección del mismo actuaron y aún actúan dentro de nuestra disciplina modelos preconcebidos sobre lo que es estudiable. Podría decirse aún más: que el cambio o transformación del objeto antropológico ha generado la puesta a prueba de determinados métodos y modelos teóricos y ha exigido su revisión cuando no la elaboración de otros nuevos, cada vez más refinados y complejos. Hasta el punto de que puede parecer que estos sucesivos cambios de objeto han llegado a transformar la identidad y sentido de la propia disciplina.

Como justificación de este tipo de enfoques, a menudo limitados y que impedían la conexión de la escala y nivel estudiados con órdenes 
mayores de significación, se ha aludido a la dificultad de transformar la metodología antropológica más tradicional para enfrentarse a las complejidades de las otras esferas - así, la urbana- como si fuera la metodología y no el marco conceptual lo que determina - y define- la sustancia antropológica. Los problemas y no sólo la manera de estudiarlos.

Ha habido, en apariencia, una ampliación progresiva de los objetos que parecían estudiables desde el punto de vista antropológico. De los lugares exóticos, donde vivían comunidades pretendidamente primitivas se pasó a la antropología del Mediterráneo. Y del estudio de esas comunidades a las campesinas. De los antropólogos que hacían su trabajo de campo en Polinesia o África a los que elegían su comunidad, su pueblo, en algún país de la Europa mediterránea. Como ha recordado Julian PittRivers (2000), uno de los fundadores de la llamada Antropología del Mediterráneo, este cambio no era tan novedoso. Los fundadores británicos de la disciplina habían tenido una formación clásica o bíblica, venían del estudio del clasicismo que es como decir de la antigüedad mediterránea con Roma o lo judeo-cristiano en el centro del espectro. De ahí se pasaría a estudiar a los "primitivos contemporáneos" como eslabones perdidos que explicaban o ayudaban a comprender los orígenes y devenir de la humanidad. No hay que olvidar América del Norte y del Sur como otros espacios privilegiados de encuentro con lo primitivo casi siempre en referencia a fuentes también bỉblicas o clásicas. La antropología urbana constituiría en este itinerario cambiante otro paso más. Pero no el último. El desafío siguiente es, probablemente, el del estudio de una aldea más que "global" fantasma o elusiva, el de unas comunidades en cierto modo invisibles por lo difícil de su localización. Un pueblo pequeño, una comunidad tenida como clásica encierra hoy casi tanta variedad de "registros" en un sentido no sólo lingüístico, sino también cultural, como una ciudad, en virtud de la globalización que se ha producido.

El cambio del objeto en antropología ha impuesto a sus practicantes una constante revisión de métodos en el último siglo. Como ha señalado María Cátedra los antropólogos han sido "los últimos en acceder al medio urbano en lo que se ha llamado la tercera revolución en antropología" (Cátedra 1997). Según este enfoque tres habrían sido las principales "revoluciones" que se produjeron durante ese periodo de tiempo en la disciplina y las tres tienen que ver con esa transformación del objeto que se ha visto desplazado de los primitivos a los campesinos y de éstos a los ciudadanos. De los grupos exóticos o "salvajes de fuera" a los "salvajes de dentro" y de ellos a los "ciudadanos" como nosotros. Un último paso, del que quizá no hemos tomado suficiente consciencia, y que la antropología ha empezado a dar, es el que tiene que ver con la 
deslocalización o traslocalización de los saberes que ya no pueden ser estudiados en relación con comunidades o territorios concretos. Medios como la televisión o Internet generan la transmisión de información y conocimientos más allá de los niveles clásicos o convencionales de comunicación. Es un fenómeno bastante general, al respecto, la pérdida o -al menos- transformación "del sentido de lugar" (Appadurai 1996). Y esos nuevos espacios en que se comparte la cultura originan, a su vez, una nueva documentación. La transmisión oral puede aparecer, provisionalmente fijada por escrito, en Internet o en los periódicos, como rumores que pasan a ser noticias. Y éste es, de hecho, el caso de muchos bulos y leyendas que se transmiten de ese modo actualmente. Ha escrito Abu-Lughod (1999: 13-15):

Las etnografías de la televisión (porque sus textos culturales son producidos en otra parte e insertados dentro de ámbitos domésticos, comunidades y naciones) vienen a confirmar, en nuestra opinión, la necesidad de repensar la noción de cultura tal como se ha utilizado en singular, como un conjunto compartido de significados, distinto de aquellos sostenidos por otras comunidades algunas veces llamadas también "culturas" [...]. Los encuentros que la televisión estimula entre mundos vividos, sensibilidades e ideas hacen especialmente problemática la noción de que las culturas son comunidades localizadas de gente.

$\mathrm{Y}$ es cierto que el concepto de "comunidad" ha sido clave en la teoría antropológica (y de las ciencias sociales), así como determinante para una cierta forma de practicar la etnografía. Hablar de "comunidades deslocalizadas" puede parecer paradójico (o una contradicción en términos), ya que dentro de esa teoría y prácticas a las que nos referimos el factor local y el aspecto territorial han tenido, tradicionalmente, una gran importancia para la definición del propio vocablo en nuestras disciplinas. Sin embargo, es un hecho también que los límites conceptuales que servían para caracterizar el término han variado en las últimas décadas y que la evolución que ha experimentado al respecto la idea de "comunidad" está ocasionando transformaciones profundas en la propia delimitación del campo que puede ser objeto de estudio de los antropólogos. Desde la acepción de "comunidad" en su sentido más primigenio y específico de "comunidad cerrada" o "comunidad de aldea" (Redfield 1956), hemos pasado a "otras significativas acepciones, mucho más complejas, espejo sin duda de la multiplicidad de las formas culturales que ofrecen las agrupaciones poblacionales" (López Girón 1993).

El método de estudios de comunidad o estudios locales ha tenido, por ejemplo, cierta tendencia a ocultar las conexiones de comunidad con el orden social mayor y las instituciones nacionales. Esto, en determina- 
dos pueblos y zonas ya no es ni recomendable ni casi posible. La antropología puede - y quizá debe- rellenar algunas lagunas de la investigación sociológica tradicional con su énfasis en los intereses cualitativos, su interés por los aspectos culturales y el enfoque holístico que le caracteriza. Desde la antropología se han estudiado, durante mucho tiempo, los pueblos y ciudades como objetos separados, cuando - sin embargo- se encuentra tan dotada o más que otras disciplinas para abordar los puntos de intersección entre los niveles convencionales de pueblo, ciudad -0 capital-, comarca, región y nación. Así como las demás intersecciones entre $\longrightarrow$ dentro de- las culturas.

Se impone, seguramente, descubrir los nuevos ámbitos de comunicación en que se comparten los saberes, de escuchar las voces que resuenan en ellos, de dejar que éstas se oigan más allá de clichés y estereotipos clasificatorios, de no cosificar a la llamada cultura popular de modo que los considerados como "portadores" de la misma pierdan - tal como ocurre en tantas recopilaciones pseudoetnográficas- no sólo su rostro sino hasta su voz. Y, desde luego, su compleja realidad vital.

Porque detrás de cualquier forma de cultura hay siempre gente que la hace posible. Y podría parecer que lo que se propone es sustituir el constructo de un pueblo ancestral y ruralizante por el de un pueblo cibernético e ilocalizable no menos evanescente e inaprehensible que aquél. Reemplazar la idea de un pueblo telúrico, pegado a las esencias de la tierra, por la de un pueblo etéreo que vagaría sin lugar a través del espacio. Enfrentar una vez más, artificialmente, los conceptos de tradición y de modernidad. A las colecciones de leyendas narradas por viejos campesinos les sucederían, así, otras colecciones de leyendas urbanas transmitidas por jóvenes no menos anónimos y desconocidos. Pero no: lo que proponemos es reconstruir los contextos más amplios de transmisión que, hoy, se producen — por arduo que ello pueda resultar-, averiguar cómo, por qué y para qué se sigue creando la cultura popular, llegar hasta los sujetos que hay tras el objeto recopilable. Incluso si —como en más de una ocasión ocurrirá- descubrimos que ese sujeto somos, también, nosotros mismos.

\section{BIBLIOGRAFÍA CITADA}

ABU-LuGHOD, LILA. 1999. "Comentarios a 'writing for culture' de Christoph Brumann". Current Anthropology, suplemento: 13-15.

Agar, Michael H. 1980. The Profesional Stranger. An Informal Introduction to Ethnography. San Diego: Academic Press.

AUGÉ, MARC. 1995. Los "no lugares", espacios de anonimato. Una antropología de la sobremodernidad. Barcelona: Gedisa. 
APpadurai, ARjun. 1996. Modernity at Large: Cultural Dimensions of Globalization. Minneapolis: University of Minnesota Press.

Baussinger, Herman. 1990. Folk Culture in a World of Technology. Bloomington: Indiana University Press.

BECK, UlRICH. 1998. ¿Qué es la globalización? Falacias del globalismo, respuestas a la globalización. Barcelona: Paidós.

BEN-AmOS, DAN. 1971. "Toward a Definition of Folklore in Context". Journal of American Folklore 84: 3-15.

BLACHE, MARTHA. 1999. Folklore urbano. Vigencia de las leyendas y los relatos tradicionales. Buenos Aires: Ediciones Colihure.

CARO Baroja, Julio. 1988. Ensayo sobre la literatura de cordel. Barcelona: Círculo de Lectores.

CÁTEDRA, MARÍA. 1997. Un santo para una ciudad. Ensayo de antropología urbana. Barcelona: Ariel.

DíAz G. Viana, Luis. 1997. De lo propio extraño. Crónicas antropológicas. Madrid: Sendoa.

Dundes, ALAN. 1977. "Who Are the Folk?", en Bascom (ed.), Frontiers of Folklore: 121. Boulder: Westview Press.

Dundes, Alan y Carl R. Pagter. 1978. Work Hard and You Shall Be Rewarded. Urban Folklore from the Paperwork Empire. Bloomington: Indiana University Press.

EsPinOSA, AURELIO M., hijo. 1987. Cuentos populares de Castilla y León. vol I. Madrid: CSIC.

Fine, Gary Alan. 1992. "The Kentucky Fried Rat: Legends and Modern Society", en Manufacturating Tales. Sex and Money in Contemporary Legends: 120-137. Knoxville: The University of Tenesee Press.

GARCíA, JosÉ LuIS. 2001. "Las fronteras administrativas y sociales: su influencia epistemológica en la antropología", en M. Cátedra (ed.), La mirada cruzada en la Península Ibérica. Perspectivas desde la antropología social en España y Portugal: 21-36. Madrid: La Catarata.

GarCía CANCLINI, NÉSTOR. 1989. Culturas hibridas. Estrategias para entrar y salir de la modernidad. México, D. F.: Grijalbo.

- 1997. "De cómo Clifford Geertz y Pierre Bourdieu llegaron al exilio". Antropología 14: 3-22.

Gramsci, ANTONIO. 1988. Antología (selección, traducción y notas de Manuel Sacristán). Madrid: Siglo XXI.

GUBERN, ROMÁN. 1987. El simio informatizado. Madrid: Fundesco.

LóPEZ GIRÓN, A. 1993. "Comunidad", en A. Aguirre (ed.), Diccionario temático de antropologia: 136-139. Barcelona: Boixareu.

ORTí, ANTONIO y JOSEP SAMPERE. 2000. Leyendas urbanas en España. Barcelona: Martínez Roca.

PITT-RIVERS, JULIAN. 2000. "Las culturas del Mediterrani". Revista d'Etnología de Catalunya 16: $8-19$

REDFIELD, RoBert. 1956. Peasant Society and Culture. Chicago: Chicago University Press.

SÁNCHEZ PÉREZ, F. 2001. "Antropología social: ¿Hacia una disciplina sin sujeto de conocimiento?”, en M. Cátedra (ed.), La mirada cruzada en la Península Ibérica. Perspectivas desde la antropología social en España y Portugal: 107-120. Madrid: La Catarata. 